\title{
Effect of Geometrical Dimensions and Waste Water Temperature on the Performance of an Induced Air Flotation Unit for the Treatment of Industrial Waste Water
}

\author{
Salam J. Bash Al-Maliky \\ Environmental Engineering/ AlMustansiriya University- Iraq \\ Research Scholar and Leader in Residence/ Ohio University-USA
}

\begin{abstract}
Induced Air Flotation (IAF) systems had found great deal of interest for their high performance in oil/water separation for the treatment of municipal and industrial waste water that can be achieved with simple and cheap operation compared with other systems such as the diffused air flotation. This paper is dedicated to the study of effects of geometrical dimensions, and water temperature on the separation efficiency of IAF process that handles effluent of dairy industry. Operation of IAF was based on the best factors gained by Al-Maliky, Al-Ajawi, Al-Bayati (2009) for the treatment of effluent of dairy industry.

Results have shown that ratios higher than 1:1 (width: height) of flotation tank tend to increase the separation efficiency under the same detention time; 1.25:1, 1.5:1, 1.75:1 and 2:1 had made an addition of 4.5, 5.2, 8.3 and $10.12 \%$ to the efficiency gain made by $1: 1$. Far from $2: 1$ was appeared to have a reverse effect in reducing the separation efficiency.

The raise in waste water temperature had shown a significant role in enhancing the water/oil separation efficiency, until it reaches about $80-84{ }^{\circ} \mathrm{C}$, beyond which that efficiency tends to decrease as oil flocs tend to scrap and layer disturbances take place. An enhancement of $10-17 \%$ occurs when operating the system with waste water temperature of $80-84{ }^{\circ} \mathrm{C}$, and air flow rates of 3-5 1/min, respectively compared with that of $22{ }^{\circ} \mathrm{C}$ and the same air flow rates.
\end{abstract}

This paper was accomplished and edited with the use of logistic and technical resources of the Institute of International Education IIE, Scholars Rescue Fund SRF and College of Engineering/ Ohio University.

Keywords: Induced Air Flotation, Oil and grease, Geometric Dimension, Waste water temperature

In Induced Air Flotation process (IAF), a proportion of micro bubbles in the flotation tank form bubble-floc agglomerates, which, when sufficiently buoyant, rise to the top of the flotation tank. At a top of the tank, a sludge-layer is formed, which can be removed by either draining liquid from the top of the tank by means of a weir, or by means of a scraper or skimmer. An exit flow of lower particle content liquid is removed from a lower part of the flotation tank.

Recent applied and theoretical analyses have explored the various hydrodynamic and physicochemical parameters that determine the performance of flotation process, for the water/oil separation for both industrial and municipal waste water as an active area of research (Rosa and Rubio, 2005; Al-Shamrani et al., 2002). Al-Maliky et al. (2009) had tested the effect of air flow rate and coagulation agents on the performance of IAF unit. Separation efficiencies were in the range of $66 \%-70 \%$ with an IAF unit that operates with $3-51 / \mathrm{min}$. air flow rates treating effluents of dairy industry, and with the addition of $0.5 \mathrm{~g} / 1$ Alum, efficiencies of $96 \%$ - $99 \%$ were achieved.

This paper is dedicated to determine the extent to which the dimensions of IAF unit and water temperature (especially high temperature ranges), may affect the performance of water/oil separation as they will affect gravity/buoyancy and turbulence factors mentioned above.

\section{Flotation Mechanisms}

There are several mechanisms which may eventually lead to the attachment of a solid particle to a bubble and hence affect the performance of IAF unit. Each of these mechanisms creates a relative motion between the particle and the bubble resulting in an encounter between the two entities. The two major mechanisms responsible for the relative motion between a particle and a bubble are gravity/buoyancy and turbulence (Ramaswamy, Kar and De, 2007). Usually under practical conditions only one of these two mechanisms is 
important since it dominates over the other. Furthermore, the two mechanisms can be separated in sub-mechanisms which act simultaneously or independently for the generation of bubble-particle aggregates. The gravity/buoyancy mechanism can be divided into the contribution of the buoyant motion of the bubble and the contribution of the gravitational motion (settling) of the particle (simultaneous action). On the other hand, the turbulent mechanism can be divided into the contribution of the motion created by the local fluid velocity (small solid particles, low levels of turbulence) and the contribution of the inertial motion over and above the local fluid velocity (large particles, high levels of turbulence). In the latter case, the two sub-mechanisms do not act simultaneously, but the one prevails over the other depending on the specific turbulent flow field characteristics (Oliveira et al., 2008).

Arnold and Stewart (2008) have indicated that the operation of IAF systems increases when the water temperature increases up to $60{ }^{\circ} \mathrm{C}$. The temperature directly affects the density, viscosity and surface tension of both oil and water and hence affects the turbulence that in turn affects the inter-particular motion. Raising the temperature also increases the enhancement of bubble coalescence (Ribeiro and Mewes, 2006).

\section{Waste water characteristics for dairy industries}

Typical dairy industry Waste water may have the characteristics listed in Table 1.

\section{Oil removal efficiency}

The oil/water separation efficiency (\%E) was obtained using Eq. (1):

$$
\% E=\left(\frac{C o-C f}{C o}\right) * 100
$$

where; $\mathrm{Co}, \mathrm{C} f$ : the initial and final concentration of $\mathrm{OG}$ present in the produced water.

\section{Experimental procedure and Arrangements}

Based on the best operational parameters of Al-Maliky et. al.2009, e.g., retention time and air flow rate, for water/oil separation from the effluent of dairy industry via IAF unit (batch system), two sets of experiments were made:

1) First set of experiments were made to determine the effect of width/height ratio on the overall performance of the IAF unit. Six ratios were tested; 1:1, 1.25:1, 1.5:1, 2:1, 2.25:1 and 2.5:1.

2) Second set of experiments were made to determine the effect of water temperature on the overall performance of the IAF unit. Five temperature ranges were tested: $20-24,30-34,50-54,60-64,80-84$ and $90-94{ }^{\circ} \mathrm{C}$.

Each of single tests of the two sets above was applied for 120 minutes of operation time, without an introduction of any kind of coagulation agent and by the use of two values of air flow rates; namely $3 \mathrm{l} / \mathrm{min}$ and $5 \mathrm{l} / \mathrm{min}$.

A rectangular glass made tank was used as the flotation basin (Fig.1) that has a movable to control the width of flotation tank. An air compressor was introduced with a pressure regulator and rotameter for the supply of controlled air flow required for the duration of each test.

A $2000 \mathrm{~W}$ electric heater was used to heat the water and a temperature indicator (TI.TSG60) ranging from $0-120^{\circ} \mathrm{C}$ was applied to measure the temperature. Oil/water emulsification process was achieved via a one variable speed mixer equipped with a glass stirrer. When the water in the preparation tank reached the intended temperature, the mixer started to work with the speed of $2000 \mathrm{rpm}$ so that the oil droplets would completely be dispersed in water.

The OG measurements for samples taken from a sampling port $10 \mathrm{~cm}$ above the bottom of IAF unit to determine the overall water/Oil separation efficiency were made due to the methods presented in Standard Methods for the Examination of water and waste water (Andrew Eaton and Mary Ann Franson2005).

\section{Results and Discussions}

The general trend of performance for the IAF unit have shown no significant differences under the application of each of the $3 \mathrm{l} / \mathrm{min}$ and $5 \mathrm{l} / \mathrm{min}$ air flow rates for all width/height ratios as shown in Table.2.

The following notes may describe these trends:

1) The overall process efficiencies, as shown in Fig.2, tend to increase with the increase of width/height ratio.

2) These increments in overall efficiencies tend to slow down with ratios above 1.5:1 and 1.75:1 for $3 \mathrm{l} / \mathrm{min}$ and

$51 /$ min air flow rate respectively.

3) The percentage change in overall oil/water separation efficiency tends to decrease with width/height ratios above 2:1 for both air flow rates (Fig.3). The wider sectional distribution of air bubbles may cause an insufficient 
air/particle amount required to achieve enough bouncy force compared with the gravitational force that forces these particles to settle down.

4) Compared to that achieved with $1: 1$, width/height ratios above $2.5: 1$ have shown declination in the overall separation efficiencies for both air flow rates.

The results of second set of tests that were intended to determine the extent of effect that water temperature may exert on the overall performance of IAF unit, have shown significant efficiency gain with the application of high temperatures compared with that achieved with $22{ }^{\circ} \mathrm{C}$ temperature, for both air flow rates, as shown in Fig.4 a $\& b$. The following notes may be exerted from these figures:

1) OG concentration tends to decrease sharply for the first hour of operation after which this decrease gets more moderate form and tends to vanish after the expiry of about $120 \mathrm{~min}$.

2) The decrease in OG concentration vs time takes more sharp form under high temperatures compared with lower ones, during the same time periods for both air flow rates; e.g, with the introduction of $5 \mathrm{l} / \mathrm{min}$ air flow rate, under $80-84^{\circ} \mathrm{C}$, that concentration decreases from $1000 \mathrm{mg} / \mathrm{l}$ to about $405 \mathrm{mg} / \mathrm{l}$ during the first 30 minutes, compared to $1000 \mathrm{mg} / \mathrm{l}$ to about $590 \mathrm{mg} / 1$ under $20-24^{\circ} \mathrm{C}$. While, with the introduction of $3 \mathrm{l} / \mathrm{min}$ air flow rate, these figures were $1000 \mathrm{mg} / \mathrm{l}$ to about $524 \mathrm{mg} / \mathrm{l}$ under $80-84{ }^{\circ} \mathrm{C}$, compared to $1000 \mathrm{mg} / \mathrm{l}$ to about $640 \mathrm{mg} / \mathrm{l} \mathrm{under}$ $20-24{ }^{\circ} \mathrm{C}$, for the same period of time.

3) With the application of temperatures above $90{ }^{\circ} \mathrm{C}$, the $\mathrm{OG}$ concentrations tend to fluctuate up and down. It was visually observed that at temperatures higher than $90{ }^{\circ} \mathrm{C}$, water vapor appeared in the air space above the treated water. This phenomenon may also affect the air bubble size, bubble formation and oil-bubble coalescence.

\section{Conclusions}

The good results gained by Al-Maliky et al., (2009) with the use of induced air flotation unit for the oil/water separation from industrial waste water via the determination of proper air flow rates and operation time, have paved the way to attempt higher efficiencies and study the effect of different dimensional ratios (height/width) of the flotation tank and the waste water temperature on the overall performance as these two parameters play a significant role in the bouncy phenomenon and the internal turbulence.

The following conclusions may appear rational based on the above results:

1) The best dimensional configuration for an IAF approach (of rectangular flotation tank), for oil/water separation was proven to be via the adoption of a flotation tank of $1.75: 1-2: 1 \mathrm{width} /$ height ratio.

2) The IAF unit was proven to perform better with the introduction of water temperature in the range of $80-84{ }^{\circ} \mathrm{C}$, as compared to room temperature.

3) Higher temperatures above $90{ }^{\circ} \mathrm{C}$ would result an adverse performance scheme for IAF unit.

4) An interesting indication was that large amounts of coagulation agents that were required to improve the oil/water separation (Al-Maliky et al., 2009; Oliveira et al., 2008; Arnold and Stewart, 2008) could be overcome by the application of the above design and operational results; e.g, width/height ratios 1.75, 2:1 and/or water temperature range of $80-84^{\circ} \mathrm{C}$. That, of course, is not a final decision as another calculation should be made to compare costs and resources relevant to the application of each scheme.

\section{References}

Al-Maliky S. Bash, Al-Ajawi Haider, Al-Bayati Nidaa (2009). Study of induced air flotation for the removal of oils from the effluents of sweets and dairy industries. Proceedings of Babylon University First Scientific researches Conference. Babylon, Iraq.

Al-Shamrani A.A., James A., Xiao H., (2002). Separation of oil from water by dissolved air flotation. Colloids and Surfaces A: Physicochemical and Engineering Aspects 209, 15-26.

Andrew D. Eaton, Mary Ann H. Franson (2005). Standard methods for the examination of water and waste water. American Public Health Association.

Arnold, K.E., Stewart,M. (2008). Surface production operations-design of oil handling systems and facilities. (Vol. 1, third ed.), Gulf Publishing Co, Houston, Texas.

Journal of Food Quality (May 31 ${ }^{\text {st }}$. 2007). (Vol. 1 Issue 1, pp 73-84). Retrieved from http://www3.interscience.wiley.com/journal/118520354/home

Oliveira de Lima, L.M., da Silva, J. H., Ribeiro Patricio, A.A., de Barros Neto, E.L., Dantas Neto, A.A., de Castro Dantas, T.N. and de Alencar Moura, M C. P., (2008). Oily waste water Treatment through a separation process using bubbles without froth formation. Petroleum Science and Technology, 26:9:994-1004.

Ramaswamy, B., Kar, D.D., De, S. (2007). A study on recovery of oil from sludge containing oil using froth flotation. Journal of environmental management, (85, pp 150-154). 
Ribeiro Jr.,C.P., Mewes, D. (2006). On the effect of liquid temperature upon bubble coalescence. Chemical Engineering Science. 61:5704-5716.

Rosa J.J., Rubio J., (2005). The FF (flocculation-flotation) process. Minerals Engineering 18 (7), $701-707$.

Table 1. Waste water Characteristics for typical dairy industry (Journal of Food Quality May $31^{\text {st }} .2007$ )

\begin{tabular}{|c|c|c|}
\hline Characteristic & Amount $(\mathrm{ppm})$ & Comments \\
\hline COD & $\begin{array}{c}1000 \\
\text { Tens of thousands }\end{array}$ & $\begin{array}{c}\text { For weakest waste water } \\
\text { For strongest waste water }\end{array}$ \\
\hline BOD & $40-80 \%$ of COD & \\
\hline TSS & Several hundred to several thousand & \\
\hline OG & Several hundred to several thousand & \\
\hline
\end{tabular}

Table 2. Experimental results for operation of flotation tank with different width/height ratios

\begin{tabular}{|c|c|c|}
\hline \multirow{2}{*}{ Width/height } & \multicolumn{2}{|c|}{ Final OG concentration (mg/l) } \\
\cline { 2 - 3 } & $31 / \mathrm{min}$ & $51 / \mathrm{min}$ \\
\hline 1 & 370 & 320 \\
\hline $1.25: 1$ & 350 & 284 \\
\hline $1.5: 1$ & 334 & 271 \\
\hline $1.75: 1$ & 333 & 260 \\
\hline $2: 1$ & 330 & 251 \\
\hline $2.25: 1$ & 350 & 290 \\
\hline $2.5: 1$ & 380 & 360 \\
\hline
\end{tabular}

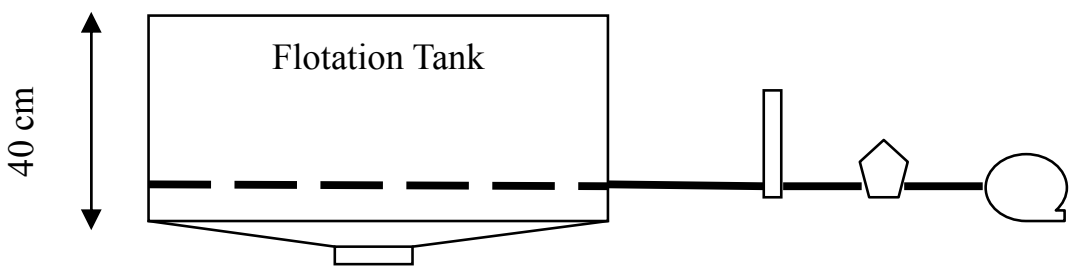

Movable vertical sector plate

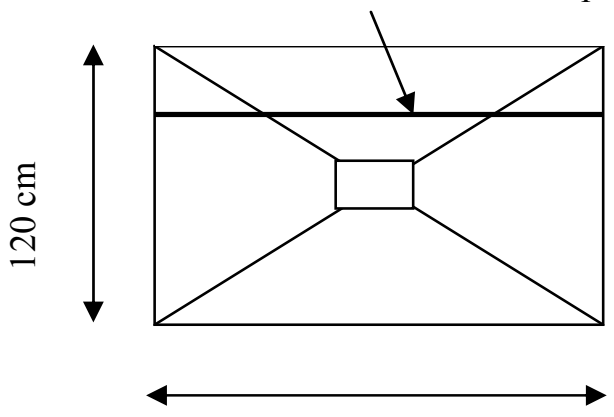

$60 \mathrm{~cm}$

Figure 1. Experimental setup for batch system of IAF 


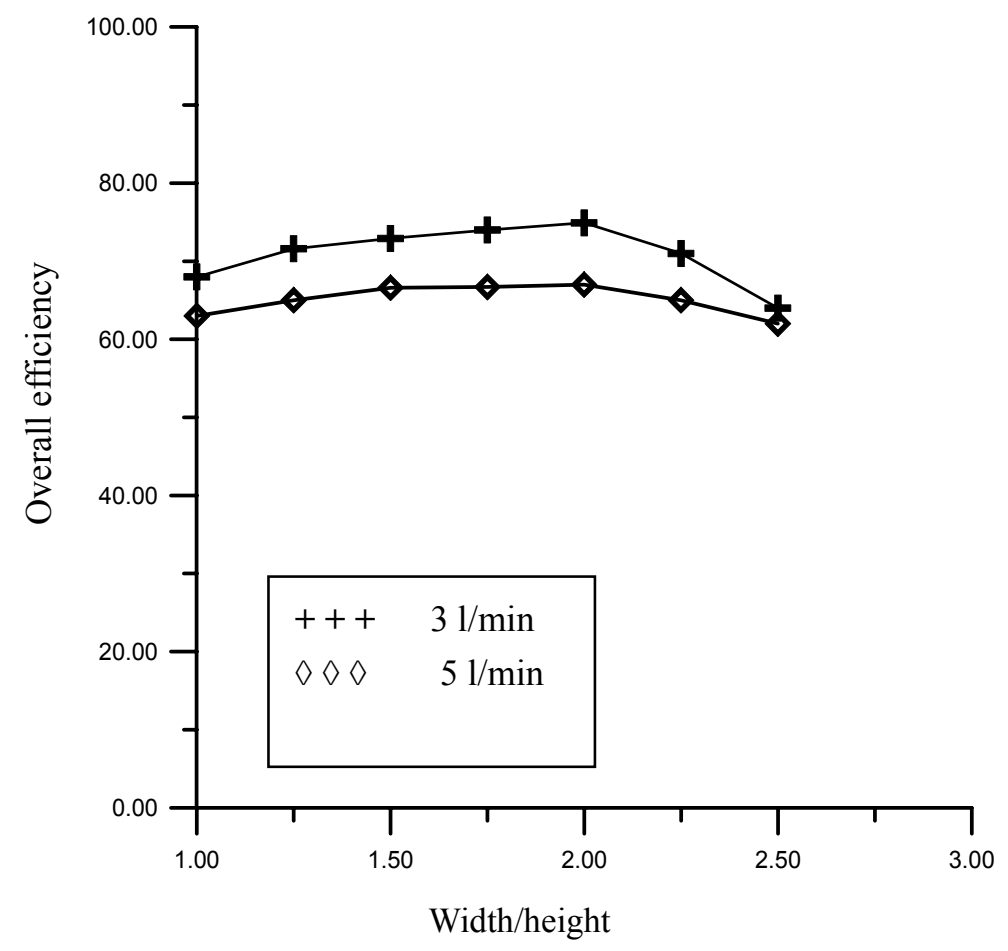

Figure. 2 Overall oil/Water separation efficiency vs width/height ratio for two air flow rates.

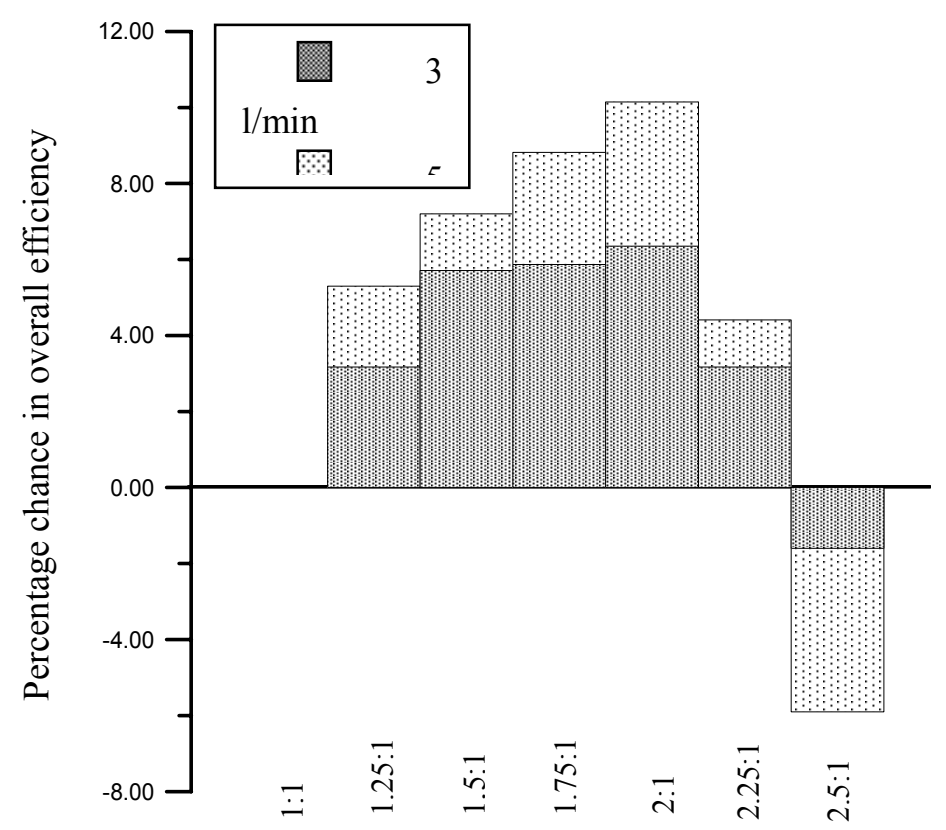

Width/height

Figure 3. Percentage change in separation efficiency vs. width/height ratio for two air flow rates. 


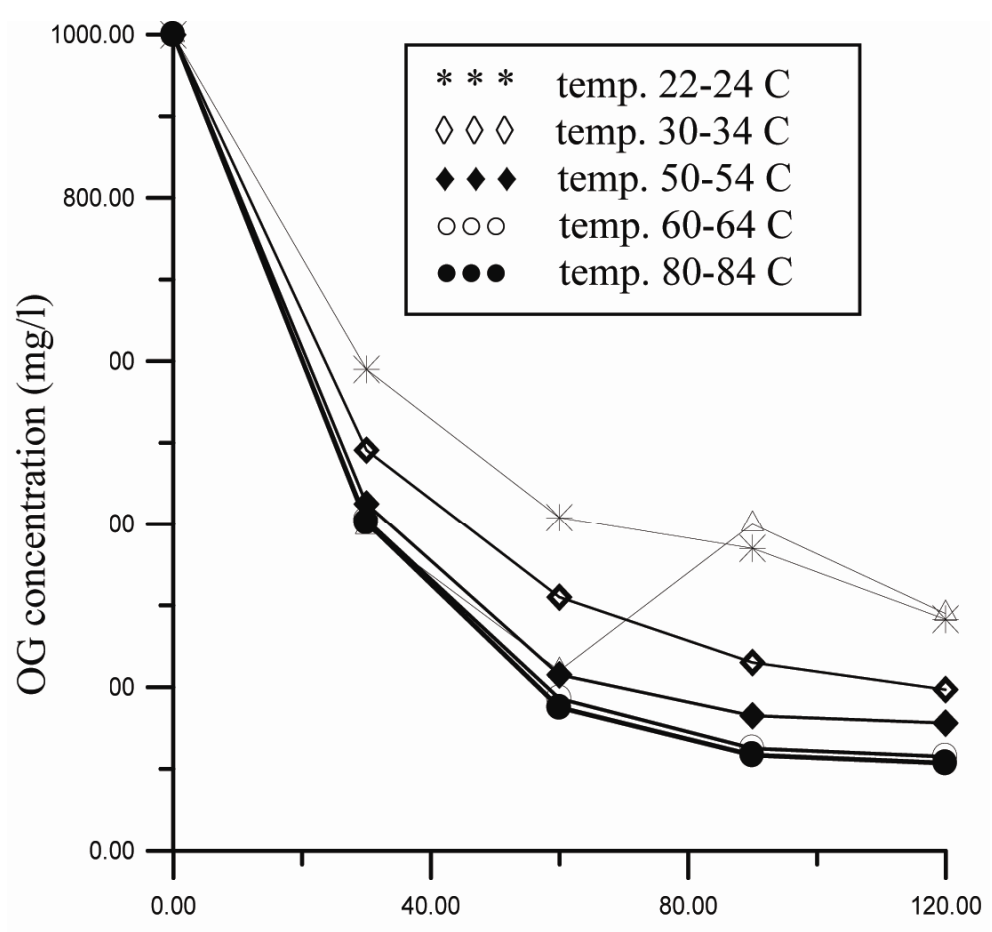

Time (min)

(a)

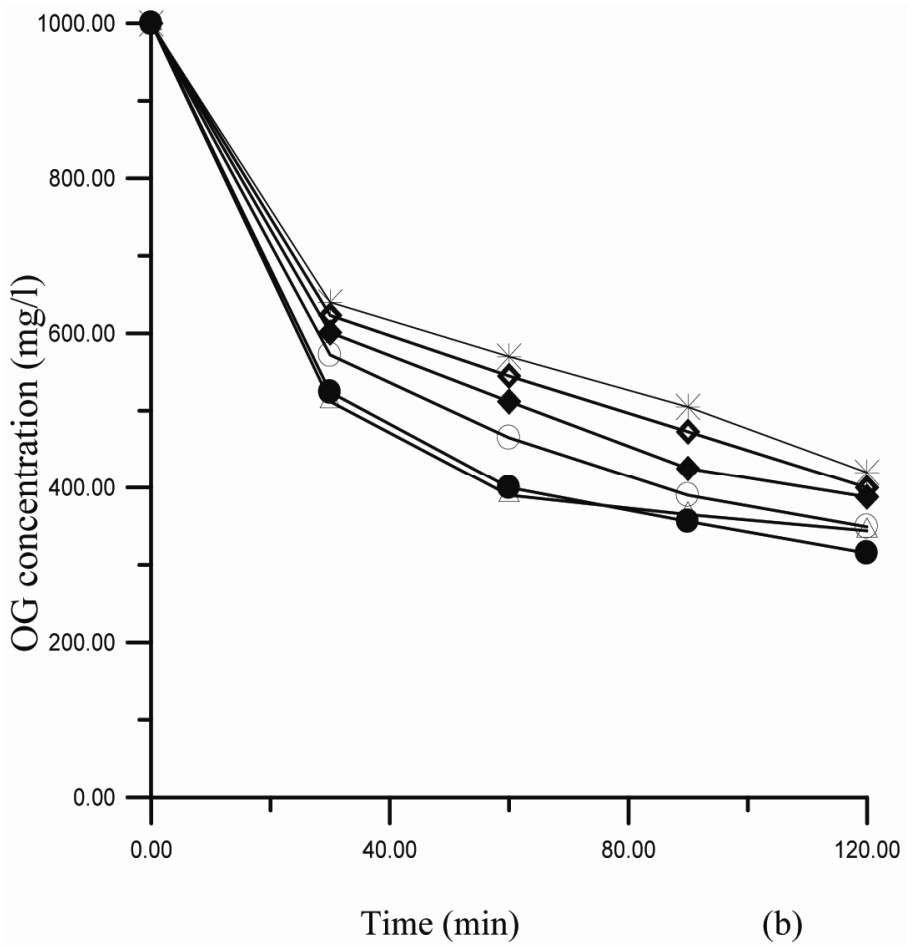

Figure 4. Bottom layer OG concentration vs. time of operation under different water temperatures.

a. Air flow rate $51 / \mathrm{min}, \mathrm{b}$. Air flow rate $31 / \mathrm{min}$ 